\title{
The Effecacy of Some Biological and Chemeical Compounds against Tuta absoluta (Meyrick) (Lepidoptera: Gelechiiidae)
}

\author{
Amany R. Sultan ${ }^{1}$, Gamal A. Morsi ${ }^{1}$, Hoda El-Fayoumi ${ }^{2}$, Abdel-Azeem S. Abdel-Baki ${ }^{*}$ \\ ${ }^{1}$ Sids Agriculture Research Station, Plant Protection Research institute, Agriculture Research Center, Giza, Egypt; \\ ${ }^{2}$ Zoology Department, Faculty of Science, Beni-Suef University, Beni-Suef, Egypt.
}

\begin{abstract}
Tomato leaf miner, Tuta absoluta is one of the most serious pest that causes significant economic losses in tomato production. Chemical insecticides is the first and effective choice for controlling T. absoluta however, the usage of such chemicals was aossciated with many environmental and health problems in addition to the development of resistance. The present study was therefore suggested to compare the efficiency of three biological insecticides with two chemical insecticides to control of T. absoluta in two seasons. Results obtained showed that Dipel 2x 6.4\% SC (Bacillus thuringiensis) was the most effective in reduction the infestation by T. absoluta. These results indicated that biopesticides could be used as best alternatives to ovoide the problems of chemical insecticides.
\end{abstract}

Keywords | Tomato, Leaf miner, Control, Insecticides, Biopesticides

Received | February 21, 2021; Accepted | June 27, 2021; Published | December 01, 2021

${ }^{*}$ Correspondence | Abdel-Azeem S. Abdel-Baki, Zoology Department, Faculty of Science, Beni-Suef University, Beni-Suef, Egypt; Email: azema1@yahoo.com Citation | Sultan AR, Morsi GA, El-Fayoumi H, Abdel-Baki AAS (2022). The effecacy of some biological and chemeical compounds against tuta absoluta (meyrick) (lepidoptera: gelechiidae). Adv. Anim. Vet. Sci. 10(1): 145-150.

DOI | http://dx.doi.org/10.17582/journal.aavs/2022/10.1.145.150

ISSN (Online) | 2307-8316; ISSN (Print) | 2309-3331

Copyright (c) 2022 Abdel-Baki et al. This is an open access article distributed under the Creative Commons Attribution License, which permits unrestricted use, distribution, and reproduction in any medium, provided the original work is properly cited.

\section{INTRODUCTION}

$\mathrm{T}$ The tomato leaf miner T. absoluta is an invasive insect pest causing severe loss of tomato production in many countries either in open field or greenhouses (Ferracini et al., 2019; Erasmus et al., 2021). Severely attacked tomato fruits lose their commercial value (EPPO, 2008). Spraying with insecticides is the principal method for T. absoluta control (Guedes et al., 1994; Picanco et al., 1996). Therefore, several studies have been carried out to evaluate the effectiveness of theses insecticides. These studies concluded that the effectiveness of chemical control was limited due to the capability of insect to rapidly develop insecticide resistant strains and most of these insecticides were harmful to both humans and the environment (Picanco et al., 1998; Siqueira et al., 2000; Lietti et al., 2005). Recently, biological insecticides, or biopesticides were crucial alternatives for the chemical ones as they are more-selective with less-polluting products (Siegwart et al., 2015). There- fore, many studies tried to compare these pesticides to find out the advantages and disadvantages of them and to provide a better sustainability for these products. Derbalah et al. (2012) evaluated the effect of indoxacarb, imidacloprid, filtrate of Bacillus thuringensis, Artemisia cina extract, clove oil and nanosilica against T. absoluta in tomato plants under greenhouse condition. They found that nanosilica was the most effective treatment against T. absoluta followed by Atremisia cina extract, combination of imidacloprid and A. cina, indoxacarb, filtrate of Bacillus thuringensis, imidacloprid, combination of indoxacarb and A. cina, and finally clove oil depending on the reduction of larvae and mine blotch counts in treated plants. Also, Lo Bue et al. (2012) realized that only combination of azadirachtin and $B$. thuringiensis was able to reduce the impact of tomato leaf miner. They concluded that the biorational insecticides are good alternative to synthetic ones. Similarly, Hanafy and E1-Sayed (2013) found that the bioinsecticides were more effective in the control of T. absoluta infesting tomato leaves 
than the chemical insecticides. In contrary, Moussa et al. (2013) show that chemical pesticides such as indoxacrab $15 \%$, spinosad $24 \%$ and emamectin benzoate $50 \%$ provide excellent control against T. absoluta, while a biopesticide $B$. thuringiensis provide moderate control. Meanwhile, Larain et al. (2014) found that soil application of cyantraniliprole significantly reduced the damage caused by the tomato leaf miner larva in both the foliage and fruit of tomato. In addition, Barakat et al. (2015) evaluated five pesticides for their efficacy in the control of T. absoluta on tomato plant. They found that Emamecitin benzoate caused highest reduction in percentage of eggs while the highest reduction in percentage of larvae occurred by Tracer and Challenger both after 7 days from application. Continuing this effort, the present study is therefore aiming to evaluate the efficiency of Dipel 2x 6.4\% SC (Bacillus thuringiensis), Lannate 90\% SC (Methomyl), Avaunt 15\% SC (indoxacarb), Radiant $12 \%$ SC (spinetoram) and Tracer 24\% SC (spinosad) against $T$. absoluta in two seasons.

\section{MATERIALS AND METHODS}

The efficiency of the tested compounds; Dipel 2x 6.4\% SC (Bacillus thuringiensis), Lannate 90\% SC (Methomyl), Avaunt 15\% SC (indoxacarb), Radiant 12\% SC (spinetoram) and Tracer 24\% SC (spinosad) was evaluated against T. absoluta in two seasons.

In two seasons, seedlings (age 40 days) of tomato variety N23 were planted at the beginning of March. All culture methods and fertilizers were followed as commonly practiced. The experimental area was divided according to the complete randomized block design including four replicate for each treatment. Each replicate was $12 \times 7 \mathrm{~m}^{2}(2 / 100$ fed.). Spray application using air-assisted knapsack sprayer (CP-3) was utilized to apply the pesticides as foliar treatment diluted with water. One afternoon spray was held against T. absoluta larvae in each growing seasons.

The untreated control plots were sprayed with water. In two seasons, spraying started with high infestation of $T$. absoluta larvae. Infestation of T. absoluta larvae was noticed before spraying and after 1,3, 5, 7, 10,15 days of spraying. The reduction percentages of T. absoluta larvae in infested leaves were calculated according to Henderson and Tilton (1955) formula. Brefiely, ten plants were randomly slected from each block, 5 leaves or fruits from each plant were examined and counted to record percentage infestation of T. absoluta. Data was presented as an average.

\section{RESULTS}

The effecacy of five compounds; Dipel 2x 6.4\%, Lannate $90 \%$, Avaunt $15 \%$, Radiant $12 \%$ and Tracer $24 \%$ against $T$. absoluta was evaluated in a field located in Beni- Suef Governorate during the first season 2014/2015. The infestation percentage of tomato leaves before and after application of these compounds were shown in Table (1). The percentage of infestation before spraying ranged between $67.25 \%$ and $79.50 \%$ in the control treatments before spraying. The percent of infestation before spraying in the treatments with Dipel 2x 6.4\%, Lannate 90\%, Avaunt 15\%, Radiant 12\% and Tracer 24\% were 71.00, 68.50, 69.75, 67.25 and 73.50 $\%$ respectively. The corresponding values after 1 day of spraying were $35.25,25.50,43.25,34.56$ and 67.50 while it reached to $44.25,44.45,60.50,76.25$ and 89.75 after 15 days of application, respectively. Pesticides treatments were varied in their toxicity against T. absoluta after 1, 3, 5, 7, 10 and 15 days of application. It was found the percentage of infestation of T. absoluta in Tracer treatment was higher than those in the other treatment while the lowest percentage of infestation after application was found in Dipel $2 \mathrm{x}$ treatments.

Mean of percentage of infestation in the different treatments was ranged from 35.69 to 71.87 compared to 88.24 $\%$ in control treatment. Dipel $2 \mathrm{x}$ and Lannate were the most effective compounds against T. absoluta, followed by Avaunt and Radiant. Tracer was the least effective, which recorded high mean of percentage of infestation reached to $71.87 \%$ compared to $88.24 \%$ in control treatment.

Table (2) showed the percent of reduction in the infestation in tomato leaves calculated after 1, 3, 5, 7, 10 and 15 days of treatment. The percent of reduction in infestation of T. absoluta indicated that Dipel 2x and Lannate caused high reduction. Tracer was the lowest effective of tested pesticides against $T$. absoluta larvae during experimental periods. It was found that the highest mean of reduction in infestation was associated with Dipel $2 x$, whereas the lowest level was associated with Tracer. All applied pesticides could be categorized into three groups according to the mean of percent reduction in infestation. The first group containing Dipel 2x (54.88\%) and Lannate (51.13\%), which gave more than $50 \%$ of reduction. The second group including Avaunt (39.83\%) and Radiant (41.41\%) which induced middle effect. The third group contained Tracer, which caused lowest protection for tomato seedling with mean of percent reduction in infestation reached to 12.18 $\%$.only. Results indicated that Dipel $2 \mathrm{x}$ and Lannate were the most efficient compounds in reducing the infestation of T. absoluta larvae in the first season of tomato leaves.

In the second season 2015/2016 of tomato leaves in the different treatments as shown in Table (3). According to mean of infestation percentage, the efficacy of tested pesticides can be arranged ascendingly as Lannate (14.81\%), Dipel 2x (23.16\%), Radiant (26.43\%), Avaunt (31.93\%) 
Table 1: Infestation percentage of tomato leaves by Tuta absoluta larva before and after application of the tested compounds during first season.

\begin{tabular}{|c|c|c|c|c|c|c|c|c|c|}
\hline \multirow[b]{2}{*}{ No. } & \multirow[b]{2}{*}{ Compounds } & \multirow[b]{2}{*}{$\%$ of infestation before application } & \multicolumn{6}{|c|}{$\%$ of infestation after application at indicated days } & \multirow[b]{2}{*}{ Mean } \\
\hline & & & 1 day & 3 days & 5 days & 7 days & 10 days & 15 days & \\
\hline 1 & Dipel $2 \times 6.4 \%$ & 71.00 & 35.25 & 31.50 & 29.45 & 30.85 & 42.85 & 44.25 & 35.69 \\
\hline 2 & Lannate $90 \%$ & 68.50 & 25.50 & 32.45 & 38.00 & 41.50 & 42.25 & 44.45 & 37.36 \\
\hline 3 & Avaunt $15 \%$ & 69.75 & 43.25 & 56.75 & 33.45 & 24.25 & 62.75 & 60.50 & 46.83 \\
\hline 4 & Radiant $12 \%$ & 67.25 & 34.56 & 32.25 & 31.00 & 22.15 & 72.00 & 76.25 & 44.70 \\
\hline 5 & Tracer $24 \%$ & 73.50 & 67.50 & 63.25 & 62.50 & 72.00 & 76.25 & 89.75 & 71.87 \\
\hline 6 & Control & 79.50 & 81.25 & 83.75 & 85.50 & 87.25 & 92.35 & 99.35 & 88.24 \\
\hline
\end{tabular}

Table 2: Percent reduction in infestation of Tuta absoluta larva after application of the tested compounds during first season.

\begin{tabular}{lllllllllll} 
& & & \multicolumn{9}{c}{ \% of infestation reduction at indicated days after application } \\
No. & Compounds & Rate & $\mathbf{1 ~ d a y}$ & $\mathbf{3}$ days & $\mathbf{5}$ days & $\mathbf{7}$ days & $\mathbf{1 0}$ days & $\mathbf{1 5}$ days & Mean \\
\hline 1 & Dipel 2x 6.4\% & $200 \mathrm{gm}$ & 51.42 & 57.89 & 61.43 & 60.41 & 48.05 & 50.13 & 54.88 \\
\hline 2 & Lannate $90 \%$ & $120 \mathrm{gm}$ & 63.58 & 55.03 & 48.42 & 44.80 & 46.90 & 48.07 & 51.13 \\
\hline 3 & Avaunt 15\% & $25 \mathrm{ml}$ & 39.33 & 22.77 & 55.41 & 68.32 & 22.55 & 30.59 & 39.83 \\
\hline 4 & Radiant 12\% & $100 \mathrm{ml}$ & 49.72 & 54.48 & 57.14 & 69.99 & 7.83 & 9.27 & 41.41 \\
\hline 5 & Tracer 24\% & $30 \mathrm{ml}$ & 10.14 & 18.31 & 20.93 & 10.74 & 10.69 & 2.29 & 12.18 \\
\hline
\end{tabular}

Table 3: Infestation percentage of tomato leaves by Tuta absoluta larva before and after application with tested compounds during second season.

\begin{tabular}{|c|c|c|c|c|c|c|c|c|c|}
\hline \multirow[b]{2}{*}{ No. } & \multirow[b]{2}{*}{ Compounds } & \multirow[b]{2}{*}{$\%$ of infestation before application } & \multicolumn{6}{|c|}{$\%$ of infestation after application at indicated days } & \multirow[b]{2}{*}{ Mean } \\
\hline & & & 1 day & 3 days & 5 days & 7 days & 10 days & 15 days & \\
\hline 1 & Dipel 2x $6.4 \%$ & 106 & 45.75 & 38.75 & 11.25 & 16.5 & 15.25 & 11.45 & 23.16 \\
\hline 2 & Lannate $90 \%$ & 99 & 22.75 & 19.0 & 17.0 & 11.6 & 10.0 & 8.5 & 14.81 \\
\hline 3 & Avaunt $15 \%$ & 93 & 46.7 & 38.4 & 21.5 & 12.0 & 18.45 & 21.5 & 26.43 \\
\hline 4 & Radiant $12 \%$ & 80 & 63.5 & 37.0 & 24.7 & 15.1 & 27.8 & 23.5 & 31.93 \\
\hline 5 & Tracer 24\% & 69 & 58 & 38.7 & 31.0 & 29.2 & 25.1 & 23.5 & 34.25 \\
\hline 6 & Control & 70 & 87 & 92 & 112 & 119 & 103 & 98 & 101.83 \\
\hline
\end{tabular}

Table 4: Percent reduction in infestation of Tuta absoluta larva after application with tested compounds during second season.

\begin{tabular}{lllllllllll} 
& & & \multicolumn{9}{c}{ \% of infestation reduction at indicated days after application } \\
No. & Compounds & Rate & $\mathbf{1}$ day & $\mathbf{3 ~ d a y s}$ & $\mathbf{5}$ days & $\mathbf{7}$ days & $\mathbf{1 0}$ days & $\mathbf{1 5}$ days & Mean \\
\hline 1 & Dipel 2x 6.4\% & 65.27 & 72.19 & 93.37 & 90.84 & 90.22 & 92.28 & 84.03 \\
\hline 2 & Lannate 90\% & 81.51 & 85.40 & 89.27 & 93.11 & 93.14 & 93.87 & 89.38 \\
\hline 3 & Avaunt 15\% & 59.60 & 68.58 & 85.55 & 92.41 & 86.52 & 83.49 & 79.36 \\
\hline 4 & Radiant 12\% & 36.14 & 64.81 & 80.70 & 88.90 & 76.38 & 79.02 & 70.99 \\
\hline 5 & Tracer 24\% & 32.37 & 57.33 & 71.92 & 75.11 & 75.28 & 75.67 & 64.61 \\
\hline
\end{tabular}

and then Tracer (34.25\%).

Regarding the efficacy mean of the examination periods, (64.61\%) reduction. The mean of percent reduction of $T$ it is clearly evident that Lannate proved to be superior to .absoluta infestation reached to 84.03, 79.36, and 70.99\%in all other treatments, which gave (89.38\%) reduction to $T$. the treatments of Dipel 2x, Avaunt and Radiant, respecabsoluta larvae, while Tracer was the last one, which cause tively (Table 4). 


\section{DISSCUSION}

Many studies have shown that chemical pesticides are more effective than biological pesticides however, the use of chemical insecticides to control this pest caused several problems such as pollution and toxicity to human and environment, harmful pesticide residues in plant, development of resistance from pest against pesticides and non-selectivity to other useful pest. Therefore, the bio-insecticides can be best alternative to avoid all these issues (Erasmus et al., 2021). Barham et al. (2012) found that chemical insecticides induced residual problems with possibility of pest resistance development and environmental pollution. Also, tomato borer resistance has been reported for the widely used chemical such as spinosad (Haddi et al., 2012; Guedes and Siqueira, 2013; Campos et al., 2015; Ferracini et al., 2019).

During the present study we therefore, compared the efficiency of two types of pesticides; biological pesticides (Dipel 2x 6.4\% SC (Bacillus thuringiensis), Radiant 12\% SC (spinetoram) and Tracer 24\% SC (spinosad)) and chemical pesticides (Lannate 90\% SC (Methomyl) and Avaunt 15\% SC (indoxacarb)) against tomato leaf miner T. absoluta. The percent of infestation before spraying in the treatments with Dipel 2x 6.4\%, Lannate 90\%, Avaunt $15 \%$, Radiant $12 \%$ and Tracer $24 \%$ were $71.00,68.50$, $69.75,67.25$ and $73.50 \%$ respectively. These results confirmed that this trail was conducted during the high level of infestation of T. absoluta and there was similarity in the percentage of infestation in the different treatments before spraying. After praying, Dipel 2x showed the highest effect followed Radiant and Tracer with lowest effect while Lannate showed the best effect off the used chemical pesticides followed by Avaunt with moderate in controlling of T. $a b$ soluta. In this study the tested pesticides; bio-insecticide Dipel $2 \times 6.4 \%$ provide excellent control against T. absoluta., that agree with, the result of Hanafy and El-Sayed (2013) show that bio-pesticides were more effective than the chemical pesticides. Also, Lo Bue et al. (2012) resulted show that only combination of Azadirachin and B. thuringiensis was able to reduce impact of tomato leaf miner and the bio-insecticides are a good alternative to chemical insecticides. Hafsi et al. (2012) informed that B. thuringiensis had an impact on T. absoluta and could be used instead of chemical insecticides.

Gonzales-Cabrera et al. (2011) and Ladurner et al. (2011) found that $B$. thuringiensis are able to reduce the impact of $T$. absoluta to very low levels. This is in agreement with result of Nazarpour et al. (2016) who reported that $B$. thuringiensis significantly suppressed the larval density and caused significant reduction in leaf, stem and fruit damage. Also, Reda and Hatem (2012) reported that the bio-pes- ticides compound B. thuringiensis proved the most potent against larvae of $T$. absoluta. Conversely, Moussa et al. (2013) show that a bio-pesticide B. thuringiensis provides moderate control.

Although, Radiant and Tracer were belonging the same group (Spinosyn) but their efficacy varied, where Radiant was more potent than Tracer against T. absoluta. Conversely, the results of Barakat et al. (2015) showed that the highest reduction percentage of larvae occurred by Tracer. Also, Braham and Hajji (2012) showed that spinosad was effective in ratio of $91 \%$ on T. absoluta. Conversely, Nannini et al. (2011) found that spinosad proved to be highly effective against tomato borer larvae T. absoluta.

Lannate and Avaunt are chemical pesticides where, Lannate was more effective than Avaunt against T. absoluta. While, the result of Moussa et al. (2013) show that chemical pesticides provide excellent control against T. absoluta, while a biopesticide $B$. thuringiensis provide moderate control. Derbalah et al. (2012) show high efficacy of indoxacarb against T. absoluta. Soliman et al. (2014) showed that Lannate and Avaunt were effective in ratio of $80 \%$ and 78\%, respectively on T. absoluta. Nazarpour et al. (2016) reported that significant short term effect of indoxacarb on the pest larvae. Indoxacarb reduced T. absoluta density and damage. Santos et al. (2011) reported that indoxacarb was numerically the best treatment reaching $96.1 \%$ mortality three days after application and $93.6 \%$ mortality seven days after application.

In conclusion T. absoluta can cause sgnficant threat to agricultural production and first choice to management strategy was applying chemical insecticides which can cause several problems to the human and envirment in addition to insecticides resistance. The results of the present study indicated that biopesticides could be used as best alternatives to ovoide the problems of chemical insecticides.

\section{ACKNOWLEDGEMENTS}

Thanks for Sids Agriculture Research Station for providing the research facilities during the present work.

\section{CONFLICT OF INTEREST}

No conflict of interest

\section{AUTHORS CONTRIBUTION}

Amany R. Sultan: Conceptualization, Methodology, Investigation, Data Curation, Writing - original draft. Gamal A. Morsi and Hoda E1-Fayoumi: Validation, Formal analy- 
OPEN OACCESS

sis, Writing - original draft.Abdel-Azeem S. Abdel-Baki: Conceptualization, Methodology, Data Curation, Writing - original draft and revising the final version.

\section{REFERENCES}

- Barakat AST, Kordy AM, Abdel Rahman TA, Gouda RM, Ibrahiem MAM (2015). Biological Activity of some Natural Plant Extracts and Bio-Pesticides against Tomato Leafminer, Tuta absoluta (Meyrick) (Lepidoptera: Gelechiidae) and their Residues on Tomato Fruits. Curr. Sci. Intl. 4 (01):1018.

-Braham M, Glida-Ghidez H, Hajji L (2012). Mangement of the tomato borer Tuta absoluta in Tunisia with novel insecticides and plant extract. Bull. OEPP 42(2):291-296. https://doi. org/10.1111/epp.2572

-Braham M, Hajji L (2012). Mangement of Tuta absoluta (Lepidoptera: Gelechiidae) with insecticides on tomato, 333-354. In: Insecticides-Pest Engineering. IntechOpen, 333-354. https://doi.org/10.5772/27812

- Campos MR, Silva TB, Silva WM, Silva JE, Siqueira HA (2015). Spinosyn resistance in the tomato borer Tuta absoluta (Meyrick) (Lepidoptera: Gelechiidae).J.Pest Sci. 88(2):405412. https://doi.org/10.1007/s10340-014-0618-y

-Derbalah A S, Morsy SZ, El-Samahy M (2012). Some recent approaches to control T. absoluta in tomato under greenhouse conditions. Afr. Entomol. 20(1): 27-34. https:// doi.org/10.4001/003.020.0104

-Desneux N, Luna MG, Guillemaud T, Urbaneja A (2011). The invasive South American tomato pinworm, T. absoluta, continues to spread in Afro-Eurasia and beyond: the new threat to tomato world production. J. Pest Sci. 84:403-408. https://doi.org/10.1007/s10340-011-0398-6

-EPPO (2005). Data sheets on quarantine pests: Tuta absoluta. EPPO Bull. 35: 434-435. https://doi.org/10.1111/j.13652338.2005.00852.x

-EPPO (2008). First report of Tuta absoluta in Spain. EPPO Reporting Service Pests and Diseases, no.1.

-Erasmus R, van den Berg J, du Plessis H (2021) Susceptibility of Tuta absoluta (Lepidoptera: Gelechiidae) Pupae to Soil Applied Entomopathogenic Fungal Biopesticides. Insects 12(6):515. https://doi.org/10.3390/insects12060515

- Ferracini C, Ferrari E, Pontini M, Saladini MA, Alma A (2019) Efectiveness of Torymus sinensis: a successful long-term control of the Asian chestnut gall wasp in Italy. J. Pest. Sci. 92:353-359.

- Gaffar S (2012). Relative comparison between parasitization efficiency of three Trichogramma species versus eggs of tomato leafminer moth, Tuta absoluta (Meyrick) on tomato greenhouse in Egypt. The Eleventh of Agricultural Development Research 27-30 March, 2012. Ain Shams Univ., Faculty of Agriculture. $168-169$.

- Gonzalez-Cabrera J, Molla O, Monton H, Urbaneja A (2011). Efficacy of Bacillus Thuringiensis (Berliner) for controlling the tomato borer, Tuta absoluta (Meyrick) (Lepidoptera: Gelechiidae). Biocontrol 56:71-80. https://doi.org/10.1007/ s10526-010-9310-1

- Guedes C, Siqueira A (2013). The tomato borer Tuta absoluta: insecticide resistaance and control failure. Plant Sci. Rev. 7(055):1-7. https://doi.org/10.1079/PAVSNNR20127055

-Haddi K (2012). Studies on insecticide resistance in Tuta absoluta (Meyrick), with special emphasis on characterization of two target site mechanisms. http://archivia.unict. It/ handle/10761/1226.

- Hafsi A, Abbes K, Chermiti B, Nasraoui B (2012). Response of the tomato miner Tuta absoluta (Lepidoptera: Gelechiidae) to thirteen insecticides in semi-natural conditions in Tunisia. EPPO Bull. 42(2): 312-316. https://doi.org/10.1111/ epp. 2575

-Hanafy HEM, El-Sayed W (2013). Efficacy of Bio-And Chemical Insecticides in the Control of Tuta absoluta (Meyrick) and Helicoverpa armigera (Hubner) Infesting Tomato Plants. AJBAS 7(2): 943-948.

-Henderson CF, Tilton EW (1955). Test with Acaricide against the brown wheat mite. J. Econ. Entomol 38:157-161. https://doi.org/10.1093/jee/48.2.157

- Ladurner E, Benuzzi M, Franceschini S (2011) Bacillus Thuringiensis var. kurstaki strain EG 2348: effect of formulation on efficacy against tomato leafminer (Tuta absoluta), IOBC/wprs Bull. 66:39-42.

-Larain P, Escudero C, Morre J, Rodriguez J (2014). Insecticide effect of cyantraniliprole on tomato moth Tuta absoluta Meyrick (Lepidoptera: Gelechiidae) larvae in field trials. Chilean J. Agr. Res. 74(2):178-183. https://doi.org/10.4067/ S0718-58392014000200008

- Leite GLD, Picanço M, Guedes RNC, Zanuncio JC (200). Role of plant age in the resistance of Lycopersicum hirsutum f. glabratum to the tomato leafminer Tuta absoluta (Lepidoptera: Gelichiidae). Sci. Hortic. 89(2) 103-113. https://doi.org/10.1016/S0304-4238(00)00224-7

- Lo Bue P, Abbas S, Peri E, Colazza S (2012). Use of biorational tomato. Special Medit. 4:39-41.

-Moussa S, Baiomy F, Sharma A, El-Adl FE (2013).The Status of Tomato Leafminer; Tuta absoluta (Meyrick)(Lepidoptera: Gelechiidae) in Egypt and Potential Effective Pesticides. Acad. J. Entomol. 6(3): 110-115.

- Nannini M, Foddi F, Murgia G, Pisci R, Sanna F (2011). Insecticides efficacy trials for management of the tomato borer Tuta absoluta (Meyrick) (Lepidoptera: Gelechiidae), A new Tomato pest in Sardinia (ITALY). Acta Hort. 917:4753. https://doi.org/10.17660/ActaHortic.2011.917.5

- Nazarpour L, Fatemeh Y, Moosa S, Ali R (2016). Short and long term effect of some bio-insecticides on Tuta absoluta Meyrick (Lepidoptera: Gelechiidae) and its cpoexisting generalist predators in tomato fields. J. Crop Prot. 5(3): 331342. https://doi.org/10.18869/modares.jcp.5.3.331

-Picanço M, Leite GLD, Madeira NR, Silva DJH, Myamoto NA (1996). Efeito do tutoramento do tomateiro e seu policultivo com o milho no ataque de Scrobipalpuloides absoluta (Meyrick) e Helicoverpa zea (Bod). Neotrop. Entomol. 25: 175-180.

-Picanço MC, Leite GLD, Guedes RNC, Silva EA (1998). Yield loss in trellised tomato affected by insecticidal sprays and plant spacing. Crop Protect. 17: 447- 452.

-Ramirez L, Ramirez N, Fuentes LS, Jiminez J, HernandezFernandez J (2010). Estandarización de un bioensayo y evaluación preliminar de tres formulaciones comerciales de Bacillus thuringiensis sobre Tuta absoluta (Meyrick) (Lepidoptera: Gelechiidae). Rev. Colomb. Biotecnol. 12(1): 12-21.

-Reda AMA, Hatem AE (2012). Biological and eradication parameters of the tomato leafminer, Tuta absoluta (Meyrick) (Lepidoptera: Gelechiidae) affected by two biopesticides. Bol. San. Veg. Plagas 38: 321-333.

- Santos AC, Freitas Bueno RCO, Vieira SS, Freitas Bueno A 
(2011). Efficacy of insecticides on Tututa (Meyricka absol) and other pests in poleomato. Bioassay 6:4. https://doi. org/10.14295/BA.v6.0.81

- Siqueira A, Guedes C, Picanco C (2000). Insecticide resistance in population of Tuta absoluta (Lepidoptera: Gelechiidae). Agric. Entomol. 2:147-153. https://doi.org/10.1046/j.14619563.2000.00062.x

-Soliman MM, Abdel-Monieum ASH, Abdel-Raheem MA (2014). Impact of some insecticides and their mixture on the population of tomato borer, Tuta absoluta (Meyrick) (Lepidoptera: Gelechiidae) and Helicoverpa armigera (Hubner) (Lepidoptera: Noctuidae) in tomato crop Upper Egypt. Phytopathol Plant Protec. 47(14): 1764-1776. https://doi.org/10.1080/03235408.2013.857226

- Tamerak SA (2011). The status of T. absoluta in Egypt. EPPO/ $\mathrm{IOBC} / \mathrm{FAO} / \mathrm{NEPPO}$ joint International Symposium on management of Tuta absoluta (tomato borer). Agadir, Morocco, November, PP. 16 - 18. 